\title{
Epithelial ovarian cancer stem cells: underlying complexity of a simple paradigm
}

\author{
Kenneth Garson ${ }^{1}$ and Barbara C Vanderhyden ${ }^{1,2}$ \\ ${ }^{1}$ Ottawa Hospital Research Institute, Centre for Cancer Therapeutics, Ottawa, Ontario, Canada K1H $8 L 6$ and \\ ${ }^{2}$ Department of Cellular and Molecular Medicine, Faculty of Medicine, University of Ottawa, Ottawa, \\ Ontario, Canada K1H $8 \mathrm{M} 5$
}

Correspondence should be addressed to B C Vanderhyden; Email: bvanderhyden@ohri.ca

\begin{abstract}
The lack of significant progress in the treatment of epithelial ovarian cancer (EOC) underscores the need to gain a better understanding of the processes that lead to chemoresistance and recurrence. The cancer stem cell (CSC) hypothesis offers an attractive explanation of how a subpopulation of cells within a patient's tumour might remain refractory to treatment and subsequently form the basis of recurrent chemoresistant disease. This review examines the literature defining somatic stem cells of the ovary and fallopian tube, two tissues that give rise to EOC. In addition, considerable research has been reviewed, that has identified subpopulations of EOC cells, based on marker expression (CD133, CD44, CD117, CD24, epithelial cell adhesion molecule, LY6A, ALDH1 and side population (SP)), which are enriched for tumour initiating cells (TICs). While many studies identified either CD133 or CD44 as markers useful for enriching for TICs, there is little consensus. This suggests that EOC cells may have a phenotypic plasticity that may preclude the identification of universal markers defining a CSC. The assay that forms the basis of quantifying TICs is the xenograft assay. Considerable controversy surrounds the xenograft assay and it is essential that some of the potential limitations be examined in this review. Highlighting such limitations or weaknesses is required to properly evaluate data and broaden our interpretation of potential mechanisms that might be contributing to the pathogenesis of ovarian cancer.
\end{abstract}

Reproduction (2015) 149 R59-R70

\section{Introduction}

Epithelial ovarian cancer (EOC) is the most lethal gynaecologic cancer, with a mortality rate of $>60 \%$. Only a very small improvement in overall survival from EOC has been realised in the last 25 years (Lowe et al. 2013). This high mortality rate and lack of tangible progress in the treatment of this disease are due, in large part, to the frequent diagnosis of the disease at advanced stages and the almost inevitable emergence of chemoresistant disease.

One model that has emerged to explain the chemoresistant fraction of EOC cells is the 'Cancer Stem Cell Hypothesis' (Rahman et al. 2011). At the core of the cancer stem cell (CSC) hypothesis is the prediction that human cancers, like their tissues of origin, have a small fraction of cells which have stem-like properties. These 'CSCs', often found to display chemoresistance, have unlimited proliferative potential through self-renewal, but can also differentiate to generate cells with limited proliferative potential that form the bulk of the tumour. Owing to the potential to self-renew residing only in this stem-like population, only these CSC can propagate the disease. Based on this strict paradigm, therapeutic interventions would need only to target the CSCs to halt the unlimited progression of the disease.

One optional facet of the CSC hypothesis is the role of the normal somatic stem cell in the aetiology of the cancer. One generalised view is that cancers develop following the transformation of the somatic stem cell in their tissue of origin. Alternatively, cancer cells may be the result of transformation of more differentiated cells that acquire properties, including self-renewal, that mirror the tissue somatic stem cell. This potential relationship between the putative CSC and the adult tissue stem cell provides an impetus to better understand the cell of origin of EOC.

This review first describes relevant approaches that have been used to identify and purify putative somatic and CSCs. Subsequently, progress in the identification of somatic stem cells within the ovarian surface epithelium (OSE) and the fallopian tube epithelium (FTE), two tissues implicated in the origin of high-grade serous EOC (HGSEOC), has been reviewed. In addition, key research that has tried to define ovarian CSCs or tumour-initiating cells (TICs) has been summarised, although the role of CSC in chemoresistance and novel strategies to target CSC, the subject of recent reviews (Ahmed et al. 2013, 
Zhan et al. 2013), have not be addressed. Finally, while the CSC hypothesis describes a simple paradigm, the underlying complexities of the assays used to define CSC or TICs are often not discussed. Importantly, this review addresses these underlying complexities by stepping outside research focused solely on EOC to examine some of the controversies surrounding the methods used to validate the CSC model. Understanding the limitations and the underlying complexities of these methods will help to guide a more accurate understanding of the roles of CSC or TICs in HGSEOC.

\section{Approaches for identifying somatic and CSCs}

The search for ovarian/fallopian somatic stem cells and ovarian CSCs has largely been based on the exploitation of properties that are associated with 'stemness' in other systems, notably the relative quiescence of somatic stem cells and the expression of specific 'stemness' markers.

\section{Labelling of quiescent somatic stem cells}

The chromatin of dividing cells can be labelled either by incorporation of bromodeoxyuridine (BrdU) into newly synthesised DNA or the integration of the fluorescent histone H2B GFP fusion protein (H2B-GFP) into the core histones of newly formed chromatin. A sufficiently long labelling period (exposure to $\mathrm{BrdU}$ or transient induction of H2B-GFP expression) allows labelling of not only proliferative cells, but also a subset of the somatic stem cells that divide during this period. While differentiated post-mitotic cells do not label and proliferative cells lose their DNA or chromatin label during subsequent rounds of replication once the label has been removed, the somatic stem cells remain labelled for extended periods of time due to their relative quiescence and can be visualised in situ as label-retaining cells (LRC). While LRC define a subset of the somatic stem cells that replicated during the labelling phase, they may also identify proliferative cells that exited the cell cycle during or immediately following the labelling phase. Therefore, while LRC provide a tentative indication of stemness, additional biological evidence is essential to support this conclusion.

\section{Identification of somatic and CSCs by marker expression}

The search for the markers of ovarian CSCs or the corresponding somatic stem cells has exploited the expression of markers defined in other cancer/somatic stem cell systems. Markers that have played a role in defining ovarian cancer/somatic stem cells include markers assayed by function (SP analysis and Aldefluor assay) or by cell surface expression (CD44, CD133, CD24, EPCAM, CD117, LY6A, LGR5). Although the exact mechanistic roles of many of these markers in ovarian CSC have not been established, a brief description of these markers and their potential biological functions, when known, are presented below.

\section{Side population}

Embryonic, somatic stem cells and CSC have frequently been observed to express heightened levels of the ATPbinding cassette (ABC) family of transporter proteins such as ABCG2 (Zhou et al. 2001). Elevated ABCG2 expression may serve to protect the genome of stem cells through the efflux of endogenous compounds which contribute to the elevated levels of reactive oxygen species, which in turn can lead to increased DNA damage (Dean et al. 2005). The cells with high levels of ABCG2 are able to efflux a variety of drugs, and can be identified and purified by FACS because of a 'SP' of cells that exhibit low Hoechst staining due to efflux of this fluorescent dye (Golebiewska et al. 2011). SP cells have frequently been found across many research platforms to enrich for cells with stem-like properties (Challen \& Little 2006).

\section{Aldefluor}

Aldehyde dehydrogenase (ALDH) enzymes catalyse the oxidation of aldehydes into carboxylic acids and are encoded by 19 different isoforms in human (Marcato et al. 2011). A subset of ALDH isoforms, most notably ALDH1A1, has been found to be upregulated in somatic and CSCs and may play roles in the detoxification of aldehydes, retinoic acid signalling and other cellular processes (Marcato et al. 2011). A fluorescent substrate of ALDH, Aldefluor, allows the identification and purification of ALDH1-expressing cells (Storms et al. 1999). ALDH activity, measured by Aldefluor, has been shown to be a useful marker for somatic and CSCs in a broad variety of systems (Marcato et al. 2011).

\section{$\mathrm{CD} 44$}

CD44, the hyaluronate receptor, has been frequently implicated as a marker of both somatic and CSCs (Zoller 2011). Understanding the role of CD44 in CSCs is complex, given the potential for numerous alternatively spliced transcripts generating distinct cell surface membrane proteins (Fig. 1). CD44 is a dynamic molecule in which variable exons can introduce new functionalities into the expressed protein and proteolytic cleavage of membrane-bound CD44 can release both an extracellular soluble form as well as an intracellular domain (Okamoto et al. 2001, Williams et al. 2013). Similar to NOTCH, CD44 is a substrate of $\gamma$-secretase, and the released intracellular domain bearing a nuclear localisation signal is able to enter the nucleus and participate directly in transcriptional control mediated by the transcriptional coactivator CBP/p300 (Nagano \& Saya 2004). Despite the importance of 


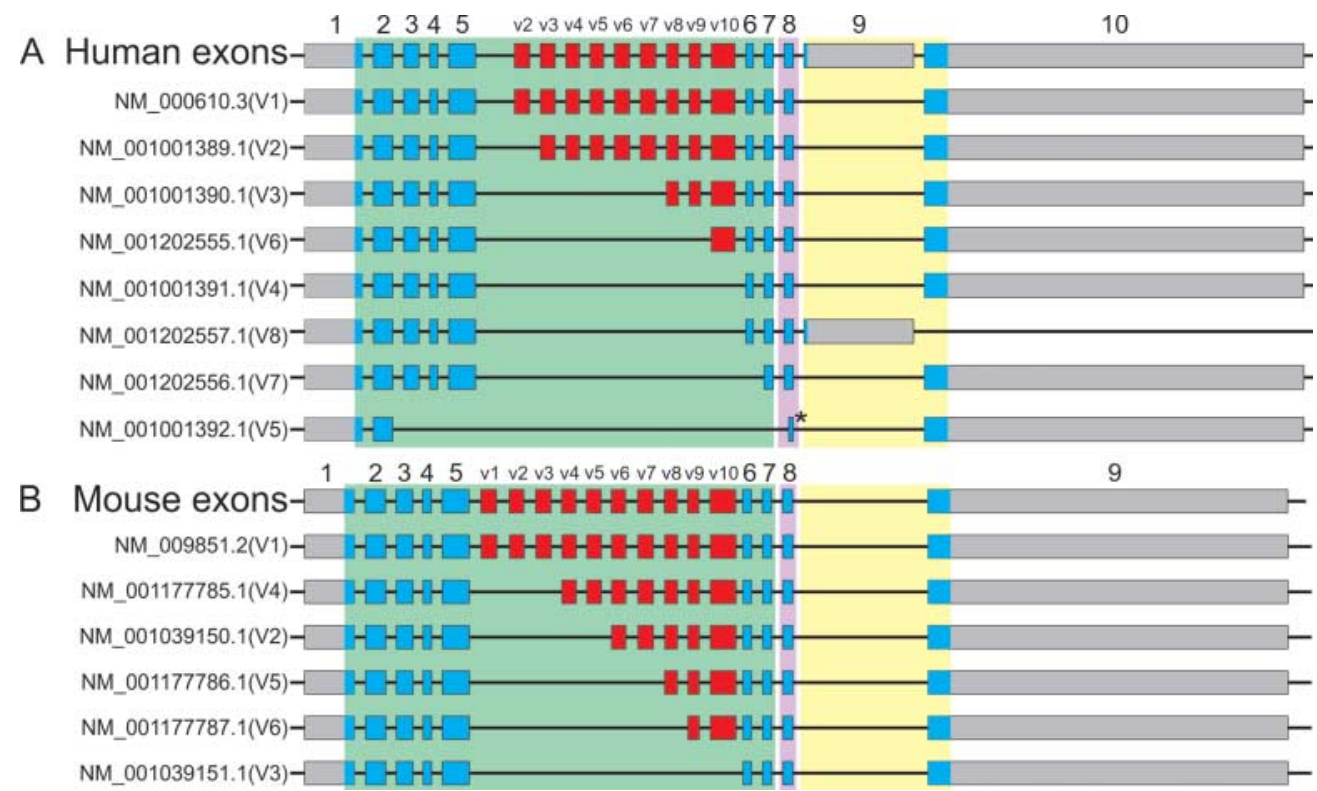

Figure 1 Standard and variant exons of human and mouse CD44. Exons for human (A) and mouse (B) CD44 genes are indicated with non-coding regions in grey, coding regions of standard exons in blue and coding regions of the alternatively spliced variant exons in red. Teal, mauve and yellow background boxes define exons which code for extracellular, transmembrane and cytoplasmic protein domains, respectively. Shown with accession numbers are exon usage maps of $C D 44$ transcripts annotated in the RefSeq database for human (V1-V8) and mouse (V1-V6). An alternate splice acceptor for exon 8, in the human transcript V5 is indicated with an asterisk. The CD44 standard form (CD44s) is shown for human (V4) and mouse (V3). Exons are drawn to scale with exon 5 representing 231 (human) or 222 (mouse) base pairs. CD44 exon maps are based on alignments of CD44 mRNA and genomic sequences from the RefSeq database (Pruitt et al. 2014).

post-transcriptional and post-translational processing, expression of CD44, as determined frequently by antibodies reactive with most isoforms, has been useful for the identification of subpopulations of cells enriched in stem-like properties (Zoller 2011).

\section{CD133}

CD133, or prominem-1, encodes a transmembrane protein of unknown function (Grosse-Gehling et al. 2013). While not analysed in depth in EOC models, different CD133 isoforms can be generated through the use of alternate promoters, alternative splicing and altered glycosylation. Immunodetection of CD133 may not always reflect protein levels as epitope masking may prevent antibody binding under certain conditions as has been observed for the commonly used AC133 antibody (Grosse-Gehling et al. 2013). Despite these caveats, CD133 has emerged as an important marker defining the subpopulations of cells with enriched CSC phenotypes (Grosse-Gehling et al. 2013).

\section{CD24}

CD24 encodes a glycosylphosphatidylinositol-linked cell surface ligand for P-selectin. CD24 mediates the adhesion of tumour cells with activated endothelial cells and platelets which express P-selectin. The expression of CD24 in numerous human cancers and its role in metastasis underpin the interest in its potential role as a CSC marker. CD24 expression has been used as both a positive and negative marker for CSCs (Jaggupilli \& Elkord 2012).

\section{Epithelial cell adhesion molecule}

Epithelial cell adhesion molecule (EPCAM) is a transmembrane molecule that plays a role in cell adhesion, migration and proliferation. EPCAM participates in epithelial tight junctions and can also be cleaved by proteases, including $\gamma$-secretase, to release both an extracellular domain and an intracellular domain which translocates to the nucleus to play a role in transcription (Imrich et al. 2012). While cell surface expression of EPCAM serves as a potential marker of CSC, its role in CSC may be mediated by the intracellular domain (Imrich et al. 2012).

\section{CD117}

CD117, encoded by the $c-K I T$ proto-oncogene, is the tyrosine kinase receptor for stem cell factor. CD117 initiates a broad program of signal transduction which mediates cell survival, migration and proliferation (Lennartsson \& Ronnstrand 2012). Interest in CD117 as a putative marker of stem cells derives from both its biological functions as well as its observed expression in primordial germ cells (Hoyer et al. 2005) and hematopoietic stem cells (Okada et al. 1991). 


\section{$\angle Y 6 A$}

LY6A encodes a glycosylphosphatidylinositol-linked cell surface antigen of largely unknown function. While LY6A is frequently used to identify stem and progenitor cells in mouse, LY6A does not have a human homolog, restricting the use of this marker to murine studies (Holmes \& Stanford 2007).

\section{LGR5}

LGR5, encoded by a WNT-target gene, was first recognised as a marker of intestinal stem cells (Barker et al. 2007). LGR5 and its ligand, R-spondin, function to enhance WNT signalling in response to low-dose WNT proteins (de Lau et al. 2012). The development of an Lgr5-eGFP-iresCreERT2 knock-in mouse allows the lineage tracing and fate determination of stem cells expressing LGR5 (Barker et al. 2007). Lineage tracing experiments using this knockin mouse has revealed a role for LGR5 in stem cells in a wide variety of tissues (Koo \& Clevers 2014).

\section{Summary of potential CSC markers}

In general, the use of the above markers to search and define ovarian CSCs is based on their empirical association with stemness in other systems. The exact functions of these markers, which are relevant to 'stemness', are poorly understood due to either a current lack of understanding of the biological functions of the marker, or frequently the lack of information correlating the varied isoforms, splicing variants or substrates to stem cell function.

Similar confusion surrounds the role of many of these markers in determining the prognosis for ovarian cancer patients. Differences in methodology for marker detection and, importantly, the exact method for scoring marker expression are the reasons often cited for conflicting reports in the literature. In particular, the decisions for establishing the thresholds for positive marker expression become critical given that the expression of a CSC marker may be highly relevant even when it is restricted only to rare cells within the tumour.

\section{Somatic stem cells; precursors to HGSEOC Tissue of origin of HGSEOC}

Historically, the origin of human EOC was presumed to be in the OSE, or in the epithelial lining of inclusion cysts that had arisen from the OSE (Bell \& Scully 1994, Feeley \& Wells 2001, Bell 2005, Auersperg et al. 2008, Pothuri et al. 2010). Recently, growing evidence has challenged this theory and identified the secretory cell of the distal fallopian tube as the putative EOC precursor (Dubeau 1999, Piek et al. 2001, Carcangiu et al. 2004, Lee et al. 2007, Carlson et al. 2008, Folkins et al. 2008, Jarboe et al. 2008, Mehra et al. 2011). The balance of evidence suggests that the distal FTE is a major site of origin of
HGSEOC; however, the OSE or derived cortical inclusion cysts are likely to also contribute progenitors to this disease (Roh et al. 2009, Crum et al. 2012, 2013).

\section{Somatic stem cells of the OSE}

While the OSE has been suggested to be largely composed of somatic stem cells (Bowen et al. 2009), a number of recent studies have sought to attribute stem cell properties only to the subsets of cells on the ovary. The somatic stem cells in the OSE have been investigated in three distinct contexts: potential stem cells able to regenerate germ cells (Parte et al. 2011, Patel et al. 2013, Virant-Klun et al. $2013 a, b)$, potential stem cells that give rise to granulosa cells (Hummitzsch et al. 2013), and more traditional somatic stem cells whose role is to replenish the OSE following ovulatory wounding (Szotek et al. 2008, Motohara et al. 2011, Gamwell et al. 2012, Usongo \& Farookhi 2012, Auersperg 2013, Flesken-Nikitin et al. 2013, Ng et al. 2014). While this review focuses briefly on studies that have addressed somatic stem cells that are thought to be required for ovulatory wound repair, the relationship with the HGSEOC of the two former potential stem cell pools cannot be discounted.

The first rigorous search for an OSE stem cell exploited the relative quiescence of the somatic stem cells using chromatin labelling with both BrdU and H2B-GFP. The LRCs were identified in murine OSE 3 months after transient labelling (Szotek et al. 2008). Importantly, the LRCs were able to enter a proliferative phase during ovulation in vivo and to have enhanced growth potential in vitro.

Two other studies have identified sporadic residents of the OSE as potential somatic stem cells. Gamwell et al. (2012) have examined candidate markers in the SP fraction of cultures of murine OSE. SP cells derived from murine OSE were enriched in the stem cell markers $L Y 6 A$ and CD117 (Gamwell et al. 2012). LY6A ${ }^{+}$cells were sphere forming in vitro and are rare residents of the OSE in vivo. WNT signalling is frequently associated with somatic stem cells; in the adult mouse, potential adult stem cells with active WNT signalling were identified in low numbers $(\sim 0.2 \%)$ in the OSE in vivo and were found to be enriched in the drug-resistant SP fraction in vitro (Usongo \& Farookhi 2012). It is unclear whether cells described in these three studies (Szotek et al. 2008, Gamwell et al. 2012, Usongo \& Farookhi 2012) describe similar overlapping populations of cells.

As opposed to the identification of rare cells within the OSE, Motohara et al. (2011) identified clusters of EPCAM-expressing cells in the murine ovarian stroma just below the OSE layer. EPCAM ${ }^{+}$cells did not express cytokeratin 8 (CK8) in contrast to OSE (EPCAM $^{-}$and $\mathrm{CK}^{+}{ }^{+}$. Sorted $\mathrm{EPCAM}^{+}$cells, but not $\mathrm{EPCAM}^{-}$cells, were able to differentiate into $\mathrm{EPCAM}^{-} / \mathrm{CK}^{+}$cells in matrigel, forming spherical cysts. EPCAM ${ }^{+}$cells were able to grow as spheres on non-adherent plates and were sensitive to induced tumourigenesis following 
knockdown of $p 53$ and induced expression of KRAS ${ }^{\mathrm{G} 12 \mathrm{~V}}$ and cMYC. In a second study, murine OSEs with ALDH1 expression and enhanced sphere-forming capacity were found to be most prevalent in OSE in the hilum region of the ovary (Flesken-Nikitin et al. 2013). In vivo, ALDH1 ${ }^{+}$ cells were shown to be quiescent through long-term retention of $\mathrm{BrdU}$ and expressed the stem cell markers $L G R 5$ and $C D 133$. Exploiting transgenic mice which allow lineage tracing of cells expressing transcripts from the L $\mathrm{gr} 5$ promoter, it was shown that LGR5-expressing OSE reside predominantly in the hilum, but over time give rise to LGR5 ${ }^{-}$OSE covering the entire ovary. More recently, Ng et al. (2014) have confirmed the utility of LGR5 expression for the identification of putative OSE stem cells; however, in contrast to Fleskin-Niitin et al. (2013), LGR5 expressing cells were found not only in the hilum region, but also throughout the surface of the ovary with highest concentrations noted in inter-follicular regions and regions adjacent to ovulatory rupture wounds. Lineage tracing suggested that multiple LGR5 ${ }^{+}$cells are recruited to effect ovulatory wound repair, and the location of these LGR5 ${ }^{+}$ stem cells at inter-follicular regions may be important for the rapid repair of ovulatory wounds (Ng et al. 2014).

While most studies have been done in mice, the expression of stem cell markers (NANOG, SFRP1, LHX9, ALDH1A1 and ALDH1A2) in human OSE, cortical inclusion cysts and FTE has been assessed by immunohistochemistry (Auersperg 2013). While prevalent expression of these markers was found in all of the above noted tissues, cortical inclusion cysts showed increased ALDH1A1 and decreased SFRP1 (WNT antagonist), suggesting increased WNT signalling. In the fallopian tube, a significant enrichment of cells expressing stem cell markers was noted in the distal versus proximal end, consistent with the role of the distal fallopian tube in the initiation of HGSEOC (Crum et al. 2012).

\section{Somatic stem cells of the oviduct/fallopian tube}

Other studies have searched for somatic stem cells of the fallopian tube (oviduct in mouse) epithelium which is largely populated by either ciliated or secretory cells (Schulte et al. 1985). Two studies have exploited the quiescent phenotype of somatic stem cells and assessed the oviduct for LRC (Wang et al. 2012, Patterson \& Pru 2013). The cells identified in these two studies are phenotypically distinct based on the presence (Patterson \& Pru 2013) or absence (Wang et al. 2012) of CD117. LRC described by Wang et al. (2012) did not express LY6A, CD44, or LGR5. In human, a detailed analysis of the fallopian tube identified a basally located cell $\left(\right.$ EPCAM $\left.^{+}, \mathrm{CD}_{4} 4^{+}, \mathrm{ITAG6}^{+}, \mathrm{KRT}^{+}\right)$that did not express markers of ciliated (TUBB4) or secretory (PAX8) cells (Paik et al. 2012). This putative stem cell was able to form spheres in matrigel containing differentiated ciliated and secretory cells as well as $\mathrm{CD} 44^{+}$basally located cells. Relevant to EOC, tubal intraepithelial carcinomas (TIC) and fallopian tube serous carcinomas were found by immunohistochemistry of patient samples to stain strongly for CD44 and KRT5. In addition, while $\mathrm{CD} 44^{+} / \mathrm{KRT}^{+}$cells are rare in normal FTE, increased KRT5 and CD44 immunohistochemical staining was evident in normal appearing epithelium located within the sections of fallopian tube presenting with serous carcinomas.

\section{Somatic stem cells and epithelial cell plasticity}

Independent studies searching for somatic stem cells of the OSE or the fallopian tube/oviductal epithelium have identified varied candidates (Fig. 2). The dogma suggests a strict cellular hierarchy within tissues in which somatic stem cells are able to both self-renew and asymmetrically divide leading to the generation of progenitors which can fully differentiate into the cell types resident in the tissue. This cellular hierarchy has been challenged by recent studies (Mannik et al. 2010, Rompolas et al. 2013, Tata et al. 2013) which have shown that differentiated epithelial cells can dedifferentiate to assume the functions of the somatic stem cell. In addition, induction of epithelial-mesenchymal transition (EMT) by TGF $\beta$ or by other means has been shown to increase the stemness of both mammary (Mani et al. 2008) and ovarian surface epithelial cells (Gamwell et al. 2012). This research may indicate a greater cellular plasticity that departs from the strict dogma of stem cell hierarchy and might explain why different methodologies may identify distinct candidates with stem cell potential. More importantly, this research indicates that the somatic stem cell hierarchy may not be intrinsic to the stem cell, but

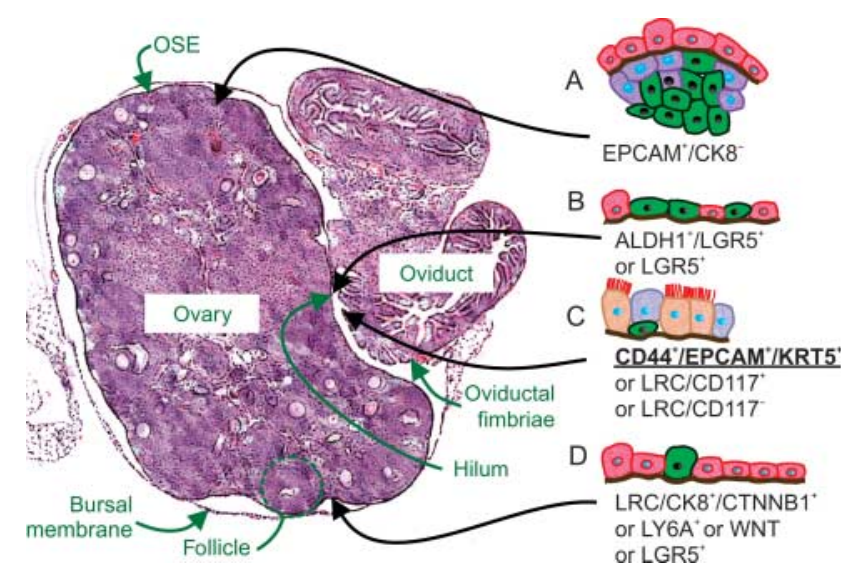

Figure 2 Putative somatic stem cells in the ovary and oviduct. Candidate somatic stem cells (green) have been found (A) in the ovarian cortex below the OSE and basement membrane, (B) in the OSE in the hilum region, $(\mathrm{C})$ in basally located cells in the fallopian tube and in two label retaining cells (LRC) of the oviduct and (D) in sporadic cells in the OSE identified as LRC, $\mathrm{LY}_{6} \mathrm{~A}^{+}$, active in WNT signalling, or in LGR5 + OSE located in the interfollicular or ovulatory repair regions. While experimental evidence for somatic stem cells was largely derived from mice, a study of human samples is identified by emboldened and underlined text in ' $\mathrm{C}$ '. 
rather may be defined by the organisation of the tissue and stem cell niche. Possibly, tissue architecture is the main determinant of stem cell identity, maintenance and regulation. This raises the concept that the stemness of cancer may not necessarily reflect an origin from somatic stem cells, but rather may result from a loss of tissue architecture and a resulting deregulation of the stem cell pool.

\section{Cancer stem cells and HGSEOC}

\section{Historical}

While the CSC hypothesis has recently provided a new course for the study of cancer, the concept of an ovarian CSC was described in 1977 (Hamburger \& Salmon 1977) with the development of a clonogenic soft agar assay. Hamburger and Salmon even highlighted two main areas of research that currently resonate through the field of CSC research: namely, the need to characterise the subpopulation of CSCs including their cell surface antigens and the need to evaluate the efficacy of therapeutic modalities for the eradication of this subpopulation of CSCs. The concept of self-renewal was further investigated by studying the kinetics of colony formation in methylcellulose of both primary EOC cells and the replating or passaging of these primary colonies to form secondary colonies (Buick \& Mackillop 1981').

'We believe that application of such simple in vitro culture techniques for studies of human tumor stem cells from primary explants will prove of clinical importance. First, the technique permits characterization of many of the biophysical properties of tumor stem cells, such as sedimentation velocity, fraction in the $S$ phase as determined by cell death as a result of treatment with tritiated thymidine, and surface antigenic features. Second, formation of in vitro colonies may prove a more sensitive indicator of occult metastatic disease than standard pathological studies. Third, such an assay could potentially be applied to develop individualized predictive trials of anticancer drugs in a manner analogous to techniques used for selection of antibacterial agents. Finally, full realization of the clinical application of bioassay of human tumor stem cell colonies with regard to their sensitivity to drugs, hormones, immunological agents, heat, and radiation could lead to major advances in clinical oncology.' (Hamburger \& Salmon 1977).

\section{Marker based identification of CSCs}

More recent approaches for studying the role of stemness in EOC are based on the identification of putative stem cell markers in EOC and the validation that these markers identify a subpopulation of cells with enhanced tumourigenic potential. In some instances, sufficient numbers of cells required for studying rare populations can be derived from primary patient material (Curley et al. 2009, Stewart et al. 2011, Kryczek et al. 2012); however frequently this is not the case. Augmentation of patient-derived tumour cells can be achieved by the in vitro expansion of primary EOC cells as spheroids grown in low attachment tissue culture dishes, a method that has also been shown for enrichment of cells with stem-like properties (Bapat et al. 2005, Zhang etal. 2008, Alvero et al. 2009, Kusumbe et al. 2009, Gao et al. 2010, Silva et al. 2011). Alternatively, more plentiful research material has been obtained following the passage of primary EOC cells through serial xenograft transplantations (Curley et al. 2009, Luo et al. 2011, Stewart et al. 2011), the use of established EOC cell lines (Hu et al. 2010, Wei et al. 2010, Silva et al. 2011) or the use of murine EOC cells (Szotek et al. 2006, Kulkarni-Datar et al. 2013, McCloskey et al. 2014) that have been made available from recently developed mouse models of EOC (Garson et al. 2012).

Rather than reviewing the literature in a strictly chronological order, the contribution of the putative CSC markers to defining an ovarian CSC will be presented.

\section{SP analysis}

The earliest marker-based purification of ovarian CSCs (Szotek et al. 2006) was the identification of an SP fraction in the MOVCAR 7 cell line derived from the MISIIR-TAg murine transgenic model (Connolly et al. 2003) of EOC. Compared with the non-SP fraction of cells, the SP fraction of MOVCAR 7 cells was more tumourigenic, showed reduced numbers of cells in S-phase (quiescence), greater proliferative potential in long-term cultures and expressed ABCG2 and the stem cell marker $C D 117(C-K I T)$. Other stem cell markers were either not differentially expressed between the SP and non-SP fractions (CD44), or not expressed at all (CD24 and LY6A).

In a separate study, the SP fraction of a primary human EOC xenograft line, PDOVCA\#1, was found to be more tumourigenic than the non-SP fraction (Moserle et al. 2008). Interestingly, unsorted cells appeared more tumourigenic than either fraction alone. It was not clear whether unsorted cells were less 'stressed' without Hoechst binding and FACS, whether a mechanism of synergy between these two cell populations led to enhanced tumourigenicty or if a significant tumourigenic population of cells was not defined by the SP or non-SP fractions. A third study showed enhanced tumourigenicity of the SP fraction for primary patient EOC ascites, OVCAR3 cells and A2780-CP cells. The SP fraction or Hoechst dim cells expressed ABCG2 and the stem cell markers OCT4, NANOG and STELLAR (Hu et al. 2010). 
While the SP assay is useful for enrichment of putative stem cells, the retention of Hoechst dye within cells in this assay reflects a dynamic interplay between drug efflux and dye retention based on DNA content. In primary human EOC, frequent aneuploidy makes this analysis challenging and ideally requires strategies to gate solely on tumour cells with the removal of normal cells from the analysis (Golebiewska et al. 2011).

\section{CD44}

CD44 was implicated in EOC when the loss of its expression in a subline of the OV1/P cell line correlated with the loss of the malignant phenotype (Teyssier et al. 1992). More recently, CD44 and CD117 were found to be co-expressed in $\sim 80 \%$ of EOC cells in spheroid cultures, but the abundance of co-expressing cells dropped to $<0.2 \%$ in xenografts derived from these spheroids or in cells from a primary patient serous adenocarcinomas. Importantly, as little as $100 \mathrm{CD} 44^{+} /$ $\mathrm{CD} 117^{+}$cells were able to form subcutaneous tumours in nude mice, whereas $\mathrm{CD} 44^{-} / \mathrm{CD} 117^{-}$failed to form tumours when 10000 (xenografts) or 100000 cells (spheroids or primary patient) cells were injected (Zhang et al. 2008). $\mathrm{CD}_{4} 4^{+}$cells from patient ascites also formed the basis of an interesting in vitro ovarian CSC model (Alvero et al. 2009). Only CD44 ${ }^{+}$cells were able to form spheroids which stably maintained a high percentage $(>90 \%)$ of $\mathrm{CD}_{4} 4^{+}$cells over multiple passages $(>20)$. This spheroid model has been exploited to examine chemoresistance, the epithelial-mesenchymal transition and the roles of pro-inflammatory pathways in CSC self-renewal (Alvero et al. 2009, Chefetz et al. 2013, Craveiro et al. 2013, Yin et al. 2013). Finally, CD44 in conjunction with CD24 and EPCAM has been used to identify an enriched tumourigenic population within the OVCAR5 cell line (Wei et al. 2010).

One limitation of the use of CD44 as a marker for the enrichment of EOC cells with stem-like properties is the heterogenous expression of this marker in EOC. In a series of human EOC patient samples, the percentage of $\mathrm{CD}_{4}{ }^{+}$cells within samples varied from 0.5 to $85 \%$ (Kryczek et al. 2012). In addition, not all studies have found that CD44 expression defines a subpopulation of cells in primary patient samples that is enriched for TICs (Stewart et al. 2011). It is also important to appreciate that most enrichment strategies based on the CD44 marker do not discriminate between the various isoforms. There has been some interest in defining isoforms which might be important for EOC pathogenesis (Shi et al. 2013), and perhaps certain isoforms of CD44 might more rigorously or consistently define an enriched CSC population.

\section{CD133}

Estimation of the percentage of EOCs that harbour subfractions of cells expressing CD133 ranges from $40 \%$
(Baba et al. 2009) to $100 \%$ (Stewart et al. 2011). Likewise, the size of CD133 expressing subpopulations within individual EOC samples shows high variability with ranges of $<15 \%$ (Baba et al. 2009, Kryczek et al. 2012) to as much as $92 \%$ (Stewart et al. 2011). While one study described enhanced tumourigenicity in clonal spheroid lines which lacked CD133 expression (Kusumbe et al. 2009), most other studies have shown, albeit inconsistently, an association of CD133-expressing cells and tumourigenic potential (Curley et al. 2009, Silva et al. 2011, Stewart et al. 2011, Kryczek et al. 2012, Kulkarni-Datar et al. 2013).

Two studies have investigated the role of combined markers CD133 and ALDH (Silva et al. 2011, Kryczek et al. 2012) and found them to define a subpopulation enriched in TICs. Similarly, CD133 combined with the murine stem cell marker $\angle Y 6 A$ defined a tumourigenic subpopulation of a murine EOC cell line (Kulkarni-Datar et al. 2013). The role of CD133 alone in defining enriched populations of CSC has also been examined in primary human tumour/ascites cells (Stewart et al. 2011) and primary human tumour cells passaged in NOD/ SCID xenografts (Curley et al. 2009). Curley et al. (2009) have found that $\mathrm{CD} 133^{+}$cells in passaged xenografts defined a subpopulation of cells that were enriched in TICs; however, residual tumourigenic potential was also found in the $\mathrm{CD}_{133^{-}}$subpopulation. Stewart et al. (2011) examined 15 EOCs in detail and reported that TICs could be entirely accounted for the CD133 ${ }^{+}$ fraction in 8/15 cases, enriched in the CD133 ${ }^{+}$fraction but also present in the $\mathrm{CD} 133^{-}$fraction in 5/15 cases or found almost entirely in the $\mathrm{CD} 133^{-}$subpopulation of cells in 2/15 cases.

While CD133 is useful to define enriched TIC populations in many EOC samples, similar to CD44, the lack of correlation in all samples suggests that the EOC TIC or CSC population may be heterogeneous with respect to the expression of this marker.

\section{CD117}

CD117, expressed in over $70 \%$ of EOC (Tonary et al. 2000), was found as a single marker to enrich for TICs derived from human EOC cell xenografts (Luo et al. 2011). The penetrance of tumourigenicity of the CD117expressing cells was 33\% when 1000 cells were injected, suggesting that CD117 alone afforded only a modest enrichment of TICs. As detailed earlier in this review, CD117 has also been used in conjunction with CD44 to define an enriched subpopulation of TICs in primary EOC cells, passaged spheroids and xenografts (Zhang et al. 2008). While CD117 shows some promise as a marker of ovarian CSC, by flow cytometry, its expression was only detected in $\sim 45 \%$ of primary EOCs (Stewart et al. 2011), limiting its use for the study of CSC in the majority of ovarian cancer cases. 
Table 1 Markers which identify ovarian caner stem cells in mouse and human.

\begin{tabular}{|c|c|c|c|c|c|c|c|c|c|c|}
\hline Species & Source $^{a}$ & CD133 & CD44 & ALDH1 & CD117 & CD24 & EPCAM & LY6A & SP & Reference \\
\hline Mouse & Cell line & & & & & & & & Positive $^{b}$ & Szotek et al. (2006) \\
\hline Mouse & Cell line & Positive $^{b}$ & & & & & & Positive $^{b}$ & & $\begin{array}{l}\text { Kulkarni-Datar et al. } \\
\quad(2013)\end{array}$ \\
\hline Human & Cell line & & & & & & & & Positive $^{b}$ & Moserle et al. (2008) \\
\hline Human & $1^{\circ}+$ Cell line & & & & & & & & Positive $^{b}$ & Hu et al. (2010) \\
\hline Human & $\begin{array}{l}1^{\circ}+\mathrm{Sph}+ \\
\quad \text { Xeno }\end{array}$ & & Positive $^{b}$ & & Positive $^{b}$ & & & & & Zhang et al. (2008) \\
\hline Human & Sph & & Positive $^{b}$ & & & & & & & Alvero et al. (2009) \\
\hline Human & Cell line & & Positive $^{b}$ & & & Positive $^{b}$ & Positive $^{b}$ & & & Wei et al. (2010) \\
\hline Human & Sph & Negative $^{\mathrm{c}}$ & & & & & & & & Kusumbe et al. (2009) \\
\hline Human & Xeno & Positive $^{b}$ & & & & & & & & Curley et al. (2009) \\
\hline Human & Sph + cell line & Positive $^{\mathrm{b}}$ & & Positive $^{b}$ & & & & & & Silva et al. (2011) \\
\hline Human & $1^{\circ}+$ Xeno & Positive $^{\mathrm{b}}$ & & & & & & & & Stewart et al. (2011) \\
\hline Human & $1^{\circ}$ & Positive $^{\mathrm{b}}$ & & Positive $^{b}$ & & & & & & Kryczek et al. (2012) \\
\hline Human & Xeno & & & & Positive $^{b}$ & & & & & Luo et al. (2011) \\
\hline Human & Sph & & & & & Positive $^{b}$ & & & & Gao et al. (2010) \\
\hline Human & Cell line & & & & & Negative $^{c}$ & & & & Shi et al. (2010) \\
\hline
\end{tabular}

SP - Side population analysis.

${ }^{a}$ Source of tumour cells was from cell lines, primary human ascites or tumours $\left(1^{\circ}\right)$, spheroid cultures (Sph) or xenografts (Xeno). ${ }^{b}$ Positive indicates that the presence of indicated marker was used for cell sorting. ${ }^{\mathrm{C}}$ Negative indicates that the absence of the indicated marker was used for cell sorting.

\section{CD24}

CD24 expression is highly variable in EOC (7-100\%; Kryczek et al. 2012) and its high prevalence in some patient samples limits its potential to enrich subpopulations. Sorting $\mathrm{CD}_{2} 4^{+}$-expressing cells from cloned spheroid cell lines showed enhanced tumourigenicity of the $\mathrm{CD}_{24}{ }^{+}$cells in nude mice over CD24 ${ }^{-}$cells (Gao et al. 2010). CD24 was also used as a marker for the tumourigenic subpopulation of cells in the OVCAR5 cell line when used in conjunction with CD44 and EPCAM, as described earlier in this review (Wei et al. 2010). In contrast to the use of CD24 to positively select for cells with enhanced tumourigenicity, CD24- $4^{-}$cells were shown to enrich for highly tumourigenic cells derived from spheroid cultures of the $3 \mathrm{AO}$ cell line (Shi et al. 2010).

\section{Summary of marker-based purification of CSC}

What is apparent from research to date is that the current markers fail to consistently enrich for the CSC phenotype across ovarian cancer samples (Table 1). In some instances, markers can positively, negatively or fail to enrich for CSC depending on the samples or study. In addition, a putative marker will not have a broad utility if it is not detectable in a sizeable proportion of ovarian cancers or if it is expressed in $100 \%$ of the cells within a tumour. This may be an indication that the utility of markers for defining TICs or CSC may depend on the environment of the cell, a concept that may explain the inconsistent correlation of these markers to a stemness phenotype.

\section{Limitations of the TIC xenograft assay}

The 'take home' message from research identifying EOC CSC presents a simple paradigm to explain chemoresistance and disease recurrence that may shape important directions for the development of novel therapeutics. While it is tempting to adopt this new paradigm, it is important to recognise the true complexity of this field of research. The gold standard for validating the presence or enrichment of CSCs is a measure of their efficiency to form tumours in immunocompromised mice; however, the underlying assumptions of this assay are controversial (Rahman et al. 2011).

\section{Mathematics of CSC enrichment}

Kern \& Shibata (2007) applied a mathematical analysis to published studies and raised some important considerations. First, the marker-based enrichment of CSC often leads to populations in which the frequency of the putative TICs is $<5 \%$. Gene expression or pathway analyses on enriched but impure subpopulations will likely be informative about the majority of cells which are not believed to be CSC. Second, as we strive toward enriching subpopulations of cells for CSC, there is a risk of excluding CSCs that are not defined by the chosen markers. This latter concern was noted by Stewart et al. (2011) in their analysis of TIC enrichment of subpopulations of EOC cells expressing the CD133 marker. Through example, in one of their samples, they reported a 25-fold enrichment of TICs in the $1 \% \mathrm{CD}_{133}{ }^{+}$ subfraction. While, superficially, this seemed quite promising, they estimated that over $80 \%$ of the TICs were actually found in the $\mathrm{CD}_{13} 3^{-}$fraction. This exemplifies why a measurement of CSC or TIC enrichment alone does not fully describe the dynamics of CSC in the cell population being analysed.

A third concern raised by Kern \& Shibato (2007) was the mathematical integrity of xenograft assays. Roughly, there should be a mathematical equivalence of the 
number of TICs in an unfractionated sample and the sum of the number of TICs in marker purified and marker excluded populations. In some instances, TICs in enriched subpopulations are many fold higher than can be accounted for in the unsorted sample ( $\mathrm{O}^{\prime}$ Brien et al. 2007, Stewart et al. 2011). In other instances, TICs in sorted populations are under represented. While under representation of TICs can be explained, in part, by gating strategies for FACS which often exclude cells with 'borderline' levels of marker expression, in some instances (Stewart et al. 2011), <5\% of expected TICs are accounted for in the positively and negatively sorted populations. Rahman et al. (2011) reviewed the possibility that marker selection, in addition to enriching for TICs, may also enrich for supporting cells or negatively select for cells inhibitory to TICs. Dramatic deviations from expected results in the TIC xenograft assay may be informing us of important mechanisms at play outside of the simple CSC paradigm.

\section{Influence of the recipient environment}

Ultimately, the TIC xenograft assay measures not only the self-renewal potential of tumour cells, but also demands that candidate cells survive isolation, purification and xenograft methodologies. In addition, properties which allow candidate cells to either migrate or establish their own niche are likely essential for successful tumour outgrowth. Perhaps, the most dramatic illustration of the role of survival in the murine host was reported for melanoma. The TIC frequency for melanoma was originally estimated to be $<0.001 \%$ when assayed in NOD/SCID mice. When similar assays were conducted using more immunocompromised mice, NOD/SCID IL2R $\gamma^{\text {null }}$ (NSG), in conjunction with the co-injection of cells with matrigel, the TIC frequency rose to over $25 \%$ (Quintana et al. 2008). Similarly, when the impact of the host mouse on measured TIC frequencies was determined for human EOC cells, significant increases in TICs were observed in 4/10 patient samples when assayed in NSG as opposed to NOD/SCID mice (Stewart et al. 2011). While these increases were not as dramatic as those observed for melanoma, they reinforce the notion that host factors also shape the outcome of TIC assays.

\section{EMT and stemness}

While the immune status of the host mouse may shape which cells are successfully able to engraft and form tumours, other cell phenotypes may also favour survival and engraftment. In the mammary somatic and CSC field, EMT has been found to transition non-stem cells into stem cells (Mani et al. 2008). A role of EMT in stemness of the OSE has also been shown (Gamwell et al. 2012). A recent experimental model of inducible EMT for squamous cell carcinoma (SCC) has elegantly shown that an ability to transition reversibly between epithelial and mesenchymal states may be important for metastasis and subsequent outgrowth of the metastatic tumour (Tsai et al. 2012). While this model was restricted to SCC, a role for EMT in metastasis of EOC has been proposed (Lili et al. 2013). Potentially, EOC cells with an enhanced capability to undergo EMT may have reduced anoikis (Huang 2013), enhanced motility and invasiveness, properties that might favour their survival, engraftment and tumourigenicity in the TIC xenograft model. While the literature does not support a consistent association of ovarian CSCs and the mesenchymal phenotype, models of a metastable phenotype which endows putative stem cells with the capability to readily transition between epithelial and mesenchymal phenotypes (Jordan et al. 2011, Thomson et al. 2011, Lu et al. 2013) may apply to EOC.

While the TIC xenograft assay is core to our attempts to understand subpopulations of EOC cells with CSC phenotypes, it is important to appreciate the shortcomings of this assay to ensure sound interpretation of the data. It is also evident that a more complete understanding of the data emerging from the TIC xenograft assay can be achieved through the limited dilution analysis, measuring the frequency of TICs in the unsorted cells, the positively sorted cells and the negatively sorted cells. While this approach is onerous due to the requirement for significant amounts of primary EOC cells and sufficient resources to undertake large-scale xenograft assays, the ensuing data will strengthen our understanding of CSC in EOC.

\section{Conclusion}

The relatively slow progress in improving the outcomes of EOC patients highlights the need for new therapeutic approaches. On the surface, the CSC hypothesis provides a simple explanation of the eventual failure of therapeutic options, the recurrence of the disease and chemoresistance. The main goal of this review was to highlight some of the recent studies which have demonstrated unique subpopulations of EOC cells with stem-like properties and to also highlight some of the controversy over the interpretation of data from the TIC xenograft assay. Highlighting such weaknesses can only broaden our interpretation of potential mechanisms that might be contributing to the pathogenesis of EOC and hopefully define new research avenues to unravel the complex phenotype of various subpopulations of EOC cells.

Currently, while markers such as CD133 and CD44 have been frequently exploited to enrich for putative CSC, no consensus has emerged. It is certainly possible that across patients and even within patients that EOC cells with stem-like properties may display a changing spectrum of markers, potentially dependent on tumour microenvironment. Also, still controversial for many solid cancers, and certainly unknown for EOC, is the possibility 
that 'stemness' does not define a type of cell within the tumour, but rather a cell state or states that can be transient and potentially induced by the tumour microenvironment. If the strict structural hierarchy of normal tissues is an important factor in the regulation of somatic stemness, the loss of a conserved architecture in tumours may lead to the dysregulation of stemness and perhaps the normal markers associated with stemness. A 'cell state(s)' model of the CSC hypothesis would still demand an understanding of the stem-like, albeit transient, CSC population to ensure efficient therapeutic targeting; however, elimination of cells in the non-CSC state would also be required to eliminate their potential to change state and contribute to continued tumour growth.

Despite the uncertainty of optimal markers defining CSC or TICs or even the strict hierarchy that may describe CSC in EOC, recent studies have defined tumourigenic populations, perhaps with robust survival properties, that are often chemoresistant and unlikely to be targeted by standard treatment regimes. Evidence of a subpopulation of ovarian CSCs, resistant to conventional therapies, provides an opportunity for a retooling of our therapeutic approach to EOC with the hope of better disease management.

\section{Declaration of interest}

The authors declare that there is no conflict of interest that could be perceived as prejudicing the impartiality of the review reported.

\section{Funding}

This work was supported by grants to B C Vanderhyden from the Canadian Cancer Society Research Institute (2011-700869) and the Canadian Institutes of Health Research (OVA-111755).

\section{Acknowledgments}

K Garson and B C Vanderhyden would like to acknowledge the colleagues within the laboratory of B C Vanderhyden and in the Centre for Cancer Therapeutics, OHRI who provided opportunities for discussion of some of the perspectives developed in this review, and to Amy C Garson for critical review of this manuscript.

\section{References}

Ahmed N, Abubaker K, Findlay J \& Quinn M 2013 Cancerous ovarian stem cells: obscure targets for therapy but relevant to chemoresistance. Journal of Cellular Biochemistry 114 21-34. (doi:10.1002/jcb.24317)

Alvero AB, Chen R, Fu HH, Montagna M, Schwartz PE, Rutherford T, Silasi DA, Steffensen KD, Waldstrom M, Visintin I et al. 2009 Molecular phenotyping of human ovarian cancer stem cells unravels the mechanisms for repair and chemoresistance. Cell Cycle 8 158-166. (doi:10.4161/cc.8.1.7533)

Auersperg N 2013 The stem-cell profile of ovarian surface epithelium is reproduced in the oviductal fimbriae, with increased stem-cell marker density in distal parts of the fimbriae. International Journal of Gynecological Pathology 32 444-453. (doi:10.1097/PGP.0b013e3182800ad5)
Auersperg N, Woo MM \& Gilks CB 2008 The origin of ovarian carcinomas: a developmental view. Gynecologic Oncology 110 452-454. (doi:10. 1016/j.ygyno.2008.05.031)

Baba T, Convery PA, Matsumura N, Whitaker RS, Kondoh E, Perry T, Huang Z, Bentley RC, Mori S, Fujii S et al. 2009 Epigenetic regulation of CD133 and tumorigenicity of $\mathrm{CD}_{133^{+}}$ovarian cancer cells. Oncogene 28 209-218. (doi:10.1038/onc.2008.374)

Bapat SA, Mali AM, Koppikar CB \& Kurrey NK 2005 Stem and progenitorlike cells contribute to the aggressive behavior of human epithelial ovarian cancer. Cancer Research 65 3025-3029. (doi:10.1158/00085472.CAN-04-3931)

Barker N, van Es JH, Kuipers J, Kujala P, van den Born M, Cozijnsen M, Haegebarth A, Korving J, Begthel H, Peters PJ et al. 2007 Identification of stem cells in small intestine and colon by marker gene Lgr5. Nature 449 1003-1007. (doi:10.1038/nature06196)

Bell DA 2005 Origins and molecular pathology of ovarian cancer. Modern Pathology 18 (Suppl 2) S19-S32. (doi:10.1038/modpathol.3800306)

Bell DA \& Scully RE 1994 Early de novo ovarian carcinoma. A study of fourteen cases. Cancer 73 1859-1864. (doi:10.1002/1097-0142(19940401)73:7< 1859::AID-CNCR2820730714>3.0.CO;2-L)

Bowen NJ, Walker LD, Matyunina LV, Logani S, Totten KA, Benigno BB \& McDonald JF 2009 Gene expression profiling supports the hypothesis that human ovarian surface epithelia are multipotent and capable of serving as ovarian cancer initiating cells. BMC Medical Genomics 271. (doi:10.1186/1755-8794-2-71)

Buick RN \& MacKillop WJ 1981 Measurement of self-renewal in culture of clonogenic cells from human ovarian carcinoma. British Journal of Cancer 44 349-355. (doi:10.1038/bjc.1981.191)

Carcangiu ML, Radice P, Manoukian S, Spatti G, Gobbo M, Pensotti V, Crucianelli R \& Pasini B 2004 Atypical epithelial proliferation in fallopian tubes in prophylactic salpingo-oophorectomy specimens from BRCA1 and BRCA2 germline mutation carriers. International Journal of Gynecological Pathology 23 35-40. (doi:10.1097/01.pgp.0000101082.35393.84)

Carlson JW, Miron A, Jarboe EA, Parast MM, Hirsch MS, Lee Y, Muto MG, Kindelberger D \& Crum CP 2008 Serous tubal intraepithelial carcinoma: its potential role in primary peritoneal serous carcinoma and serous cancer prevention. Journal of Clinical Oncology 26 4160-4165. (doi:10. 1200/JCO.2008.16.4814)

Challen GA \& Little MH 2006 A side order of stem cells: the SP phenotype. Stem Cells 24 3-12. (doi:10.1634/stemcells.2005-0116)

Chefetz I, Alvero AB, Holmberg JC, Lebowitz N, Craveiro V, YangHartwich Y, Yin G, Squillace L, Gurrea Soteras M, Aldo P et al. 2013 TLR2 enhances ovarian cancer stem cell self-renewal and promotes tumor repair and recurrence. Cell Cycle 12 511-521. (doi:10.4161/cc.23406)

Connolly DC, Bao R, Nikitin AY, Stephens KC, Poole TW, Hua X, Harris SS, Vanderhyden BC \& Hamilton TC 2003 Female mice chimeric for expression of the simian virus $40 \mathrm{TAg}$ under control of the MISIIR promoter develop epithelial ovarian cancer. Cancer Research 63 1389-1397.

Craveiro V, Yang-Hartwich Y, Holmberg JC, Sumi NJ, Pizzonia J, Griffin B, Gill SK, Silasi DA, Azodi M, Rutherford T et al. 2013 Phenotypic modifications in ovarian cancer stem cells following paclitaxel treatment. Cancer Medicine 2 751-762. (doi:10.1002/cam4.115)

Crum CP, McKeon FD \& Xian W 2012 BRCA, the oviduct, and the space and time continuum of pelvic serous carcinogenesis. International Journal of Gynecological Cancer 22 (Suppl 1) S29-S34. (doi:10.1097/ IGC.0b013e31824d7269)

Crum CP, Herfs M, Ning G, Bijron JG, Howitt BE, Jimenez CA, Hanamornroongruang S, McKeon FD \& Xian W 2013 Through the glass darkly: intraepithelial neoplasia, top-down differentiation, and the road to ovarian cancer. Journal of Pathology 231 402-412. (doi:10.1002/path.4263)

Curley MD, Therrien VA, Cummings CL, Sergent PA, Koulouris CR, Friel AM, Roberts DJ, Seiden MV, Scadden DT, Rueda BR et al. 2009 CD133 expression defines a tumor initiating cell population in primary human ovarian cancer. Stem Cells 27 2875-2883. (doi:10.1002/stem.236)

Dean M, Fojo T \& Bates S 2005 Tumour stem cells and drug resistance. Nature Reviews. Cancer 5 275-284. (doi:10.1038/nrc1590)

Dubeau L 1999 The cell of origin of ovarian epithelial tumors and the ovarian surface epithelium dogma: does the emperor have no clothes? Gynecologic Oncology 72 437-442. (doi:10.1006/gyno.1998.5275)

Feeley KM \& Wells M 2001 Precursor lesions of ovarian epithelial malignancy. Histopathology 38 87-95. (doi:10.1046/j.1365-2559. 2001.01042.x) 
Flesken-Nikitin A, Hwang Cl, Cheng CY, Michurina TV, Enikolopov G \& Nikitin AY 2013 Ovarian surface epithelium at the junction area contains a cancer-prone stem cell niche. Nature 495 241-245. (doi:10.1038/ nature11979)

Folkins AK, Jarboe EA, Saleemuddin A, Lee Y, Callahan MJ, Drapkin R, Garber JE, Muto MG, Tworoger S \& Crum CP 2008 A candidate precursor to pelvic serous cancer (p53 signature) and its prevalence in ovaries and fallopian tubes from women with BRCA mutations. Gynecologic Oncology 109 168-173. (doi:10.1016/j.ygyno.2008.01.012)

Gamwell LF, Collins O \& Vanderhyden BC 2012 The mouse ovarian surface epithelium contains a population of LY6A (SCA-1) expressing progenitor cells that are regulated by ovulation-associated factors. Biology of Reproduction 87 80. (doi:10.1095/biolreprod.112.100347)

Gao MQ, Choi YP, Kang S, Youn JH \& Cho NH 2010 CD24 ${ }^{+}$cells from hierarchically organized ovarian cancer are enriched in cancer stem cells. Oncogene 29 2672-2680. (doi:10.1038/onc.2010.35)

Garson K, Gamwell LF, Pitre EM \& Vanderhyden BC 2012 Technical challenges and limitations of current mouse models of ovarian cancer. Journal of Ovarian Research 5 39. (doi:10.1186/1757-2215-5-39)

Golebiewska A, Brons NH, Bjerkvig R \& Niclou SP 2011 Critical appraisal of the side population assay in stem cell and cancer stem cell research. Cell Stem Cell 8 136-147. (doi:10.1016/j.stem.2011.01.007)

Grosse-Gehling P, Fargeas CA, Dittfeld C, Garbe Y, Alison MR, Corbeil D \& Kunz-Schughart LA 2013 CD133 as a biomarker for putative cancer stem cells in solid tumours: limitations, problems and challenges. Journal of Pathology 229 355-378. (doi:10.1002/path.4086)

Hamburger AW \& Salmon SE 1977 Primary bioassay of human tumor stem cells. Science 197 461-463. (doi:10.1126/science.560061)

Holmes C \& Stanford WL 2007 Concise review: stem cell antigen-1: expression, function, and enigma. Stem Cells 25 1339-1347. (doi:10. 1634/stemcells.2006-0644)

Hoyer PE, Byskov AG \& Mollgard K 2005 Stem cell factor and c-Kit in human primordial germ cells and fetal ovaries. Molecular and Cellular Endocrinology 234 1-10. (doi:10.1016/j.mce.2004.09.012)

Hu L, McArthur C \& Jaffe RB 2010 Ovarian cancer stem-like sidepopulation cells are tumourigenic and chemoresistant. British Journal of Cancer 102 1276-1283. (doi:10.1038/sj.bjc.6605626)

Hummitzsch K, Irving-Rodgers HF, Hatzirodos N, Bonner W, Sabatier L, Reinhardt DP, Sado Y, Ninomiya Y, Wilhelm D \& Rodgers RJ 2013 A new model of development of the mammalian ovary and follicles. PLOS ONE 8 e55578. (doi:10.1371/journal.pone.0055578)

Imrich S, Hachmeister M \& Gires O 2012 EpCAM and its potential role in tumorinitiating cells. Cell Adhesion \& Migration 6 30-38. (doi:10.4161/cam.18953)

Jaggupilli A \& Elkord E 2012 Significance of CD44 and CD24 as cancer stem cell markers: an enduring ambiguity. Clinical \& Developmental Immunology 2012 708036. (doi:10.1155/2012/708036)

Jarboe E, Folkins A, Nucci MR, Kindelberger D, Drapkin R, Miron A, Lee Y \& Crum CP 2008 Serous carcinogenesis in the fallopian tube: a descriptive classification. International Journal of Gynecological Pathology 27 1-9. (doi:10.1097/pgp.0b013e31814b191f)

Jordan NV, Johnson GL \& Abell AN 2011 Tracking the intermediate stages of epithelial-mesenchymal transition in epithelial stem cells and cancer. Cell Cycle 10 2865-2873. (doi:10.4161/cc.10.17.17188)

Kern SE \& Shibata D 2007 The fuzzy math of solid tumor stem cells: a perspective. Cancer Research 67 8985-8988. (doi:10.1158/0008-5472. CAN-07-1971)

Koo BK \& Clevers H 2014 Stem cells marked by the R-spondin receptor LGR5. Gastroenterology 147 289-302. (doi:10.1053/j.gastro.2014.05.007)

Kryczek I, Liu S, Roh M, Vatan L, Szeliga W, Wei S, Banerjee M, Mao Y, Kotarski J, Wicha MS et al. 2012 Expression of aldehyde dehydrogenase and CD133 defines ovarian cancer stem cells. International Journal of Cancer 130 29-39. (doi:10.1002/ijc.25967)

Kulkarni-Datar K, Orsulic S, Foster R \& Rueda BR 2013 Ovarian tumor initiating cell populations persist following paclitaxel and carboplatin chemotherapy treatment in vivo. Cancer Letters 339 237-246. (doi:10. 1016/j.canlet.2013.06.014)

Kusumbe AP, Mali AM \& Bapat SA 2009 CD133-expressing stem cells associated with ovarian metastases establish an endothelial hierarchy and contribute to tumor vasculature. Stem Cells 27 498-508. (doi:10. 1634/stemcells.2008-0868)

de Lau WB, Snel B \& Clevers HC 2012 The R-spondin protein family. Genome Biology 13 242. (doi:10.1186/gb-2012-13-3-242)
Lee $Y$, Miron A, Drapkin R, Nucci MR, Medeiros F, Saleemuddin A, Garber J, Birch C, Mou H, Gordon RW et al. 2007 A candidate precursor to serous carcinoma that originates in the distal fallopian tube. Journal of Pathology 211 26-35. (doi:10.1002/path.2091)

Lennartsson J \& Ronnstrand L 2012 Stem cell factor receptor/c-Kit: from basic science to clinical implications. Physiological Reviews 92 1619-1649. (doi:10.1152/physrev.00046.2011)

Lili LN, Matyunina LV, Walker LD, Wells SL, Benigno BB \& McDonald JF 2013 Molecular profiling supports the role of epithelial-to-mesenchymal transition (EMT) in ovarian cancer metastasis. Journal of Ovarian Research 6 49. (doi:10.1186/1757-2215-6-49)

Lowe KA, Chia VM, Taylor A, O'Malley C, Kelsh M, Mohamed M, Mowat FS \& Goff B 2013 An international assessment of ovarian cancer incidence and mortality. Gynecologic Oncology 130 107-114. (doi:10.1016/j. ygyno.2013.03.026)

Lu M, Jolly MK, Levine H, Onuchic JN \& Ben-Jacob E 2013 MicroRNAbased regulation of epithelial-hybrid-mesenchymal fate determination. PNAS 110 18144-18149. (doi:10.1073/pnas.1318192110)

Luo L, Zeng J, Liang B, Zhao Z, Sun L, Cao D, Yang J \& Shen K 2011 Ovarian cancer cells with the CD117 phenotype are highly tumorigenic and are related to chemotherapy outcome. Experimental and Molecular Pathology 91 596-602. (doi:10.1016/j.yexmp.2011.06.005)

Mani SA, Guo W, Liao MJ, Eaton EN, Ayyanan A, Zhou AY, Brooks M, Reinhard F, Zhang CC, Shipitsin M et al. 2008 The epithelialmesenchymal transition generates cells with properties of stem cells. Cell 133 704-715. (doi:10.1016/j.cell.2008.03.027)

Mannik J, Alzayady K \& Ghazizadeh S 2010 Regeneration of multilineage skin epithelia by differentiated keratinocytes. Journal of Investigative Dermatology 130 388-397. (doi:10.1038/jid.2009.244)

Marcato P, Dean CA, Giacomantonio CA \& Lee PW 2011 Aldehyde dehydrogenase: its role as a cancer stem cell marker comes down to the specific isoform. Cell Cycle 10 1378-1384. (doi:10.4161/cc.10.9.15486)

McCloskey CW, Goldberg RL, Carter LE, Gamwell LF, Al-Hujaily EM, Collins O, Macdonald EA, Garson K, Daneshmand M, Carmona E et al. 2014 A new spontaneously transformed syngeneic model of high-grade serous ovarian cancer with a tumor-initiating cell population. Frontiers in Oncology 4 53. (doi:10.3389/fonc.2014.00053)

Mehra K, Mehrad M, Ning G, Drapkin R, McKeon FD, Xian W \& Crum CP 2011 STICS, SCOUTs and p53 signatures; a new language for pelvic serous carcinogenesis. Frontiers in Bioscience 3 625-634. (doi:10.2741/e275)

Moserle L, Indraccolo S, Ghisi M, Frasson C, Fortunato E, Canevari S, Miotti S, Tosello V, Zamarchi R, Corradin A et al. 2008 The side population of ovarian cancer cells is a primary target of IFN- $\alpha$ antitumor effects. Cancer Research 68 5658-5668. (doi:10.1158/0008-5472.CAN-07-6341)

Motohara T, Masuko S, Ishimoto T, Yae T, Onishi N, Muraguchi T, Hirao A, Matsuzaki Y, Tashiro H, Katabuchi $\mathbf{H}$ et al. 2011 Transient depletion of p53 followed by transduction of C-Myc and K-Ras converts ovarian stemlike cells into tumor-initiating cells. Carcinogenesis 32 1597-1606. (doi:10.1093/carcin/bgr183)

Nagano O \& Saya H 2004 Mechanism and biological significance of CD44 cleavage. Cancer Science 95 930-935. (doi:10.1111/j.1349-7006.2004. tb03179.x)

Ng A, Tan S, Singh G, Rizk P, Swathi Y, Tan TZ, Huang RY, Leushacke M \& Barker N 2014 Lgr5 marks stem/progenitor cells in ovary and tubal epithelia. Nature Cell Biology 16 745-757. (doi:10.1038/ncb3000)

O'Brien CA, Pollett A, Gallinger S \& Dick JE 2007 A human colon cancer cell capable of initiating tumour growth in immunodeficient mice. Nature 445 106-110. (doi:10.1038/nature05372)

Okada S, Nakauchi H, Nagayoshi K, Nishikawa S, Nishikawa S, Miura Y \& Suda T 1991 Enrichment and characterization of murine hematopoietic stem cells that express c-kit molecule. Blood 78 1706-1712.

Okamoto I, Kawano Y, Murakami D, Sasayama T, Araki N, Miki T, Wong AJ \& Saya H 2001 Proteolytic release of CD44 intracellular domain and its role in the CD44 signaling pathway. Journal of Cell Biology 155 755-762. (doi:10.1083/jcb.200108159)

Paik DY, Janzen DM, Schafenacker AM, Velasco VS, Shung MS, Cheng D, Huang J, Witte ON \& Memarzadeh S 2012 Stem-like epithelial cells are concentrated in the distal end of the fallopian tube: a site for injury and serous cancer initiation. Stem Cells 30 2487-2497. (doi:10.1002/ stem.1207)

Parte S, Bhartiya D, Telang J, Daithankar V, Salvi V, Zaveri K \& Hinduja I 2011 Detection, characterization, and spontaneous differentiation 
in vitro of very small embryonic-like putative stem cells in adult mammalian ovary. Stem Cells and Development 20 1451-1464. (doi:10. 1089/scd.2010.0461)

Patel H, Bhartiya D, Parte S, Gunjal P, Vedulkar S \& Bhatt M 2013 Follicle stimulating hormone modulates ovarian stem cells through alternately spliced receptor variant FSH-R3. Journal of Ovarian Research 652. (doi:10.1186/1757-2215-6-52)

Patterson AL \& Pru JK 2013 Long-term label retaining cells localize to distinct regions within the female reproductive epithelium. Cell Cycle $\mathbf{1 2}$ 2888-2898. (doi:10.4161/cc.25917)

Piek JM, van Diest PJ, Zweemer RP, Jansen JW, Poort-Keesom RJ, Menko FH, Gille JJ, Jongsma AP, Pals G, Kenemans P et al. 2001 Dysplastic changes in prophylactically removed fallopian tubes of women predisposed to developing ovarian cancer. Journal of Pathology 195 451-456. (doi:10.1002/path.1000)

Pothuri B, Leitao MM, Levine DA, Viale A, Olshen AB, Arroyo C, Bogomolniy F, Olvera N, Lin O, Soslow RA et al. 2010 Genetic analysis of the early natural history of epithelial ovarian carcinoma. PLOS ONE 5 e10358. (doi:10.1371/journal.pone.0010358)

Pruitt KD, Brown GR, Hiatt SM, Thibaud-Nissen F, Astashyn A, Ermolaeva O, Farrell CM, Hart J, Landrum MJ, McGarvey KM et al. 2014 RefSeq: an update on mammalian reference sequences. Nucleic Acids Research 42 D756-D763. (doi:10.1093/nar/gkt1114)

Quintana E, Shackleton M, Sabel MS, Fullen DR, Johnson TM \& Morrison SJ 2008 Efficient tumour formation by single human melanoma cells. Nature 456 593-598. (doi:10.1038/nature07567)

Rahman M, Deleyrolle L, Vedam-Mai V, Azari H, Abd-El-Barr M \& Reynolds BA 2011 The cancer stem cell hypothesis: failures and pitfalls. Neurosurgery 68 531-545 (discussion 545). (doi:10.1227/NEU. Ob013e3181ff9eb5)

Roh MH, Kindelberger D \& Crum CP 2009 Serous tubal intraepithelial carcinoma and the dominant ovarian mass: clues to serous tumor origin? American Journal of Surgical Pathology 33 376-383. (doi:10.1097/PAS. ob013e3181868904)

Rompolas P, Mesa KR \& Greco V 2013 Spatial organization within a niche as a determinant of stem-cell fate. Nature 502 513-518. (doi:10.1038/ nature12602)

Schulte BA, Rao KP, Kreutner A, Thomopoulos GN \& Spicer SS 1985 Histochemical examination of glycoconjugates of epithelial cells in the human fallopian tube. Laboratory Investigation 52 207-219.

Shi MF, Jiao J, Lu WG, Ye F, Ma D, Dong QG \& Xie X 2010 Identification of cancer stem cell-like cells from human epithelial ovarian carcinoma cell line. Cellular and Molecular Life Sciences 67 3915-3925. (doi:10.1007/ s00018-010-0420-9)

Shi J, Zhou Z, Di W \& Li N 2013 Correlation of CD44v6 expression with ovarian cancer progression and recurrence. BMC Cancer 13182 (doi:10.1186/1471-2407-13-182)

Silva IA, Bai S, McLean K, Yang K, Griffith K, Thomas D, Ginestier C, Johnston C, Kueck A, Reynolds RK et al. 2011 Aldehyde dehydrogenase in combination with CD133 defines angiogenic ovarian cancer stem cells that portend poor patient survival. Cancer Research 71 3991-4001. (doi:10.1158/0008-5472.CAN-10-3175)

Stewart JM, Shaw PA, Gedye C, Bernardini MQ, Neel BG \& Ailles LE 2011 Phenotypic heterogeneity and instability of human ovarian tumorinitiating cells. PNAS 108 6468-6473. (doi:10.1073/pnas.1005529108)

Storms RW, Trujillo AP, Springer JB, Shah L, Colvin OM, Ludeman SM \& Smith C 1999 Isolation of primitive human hematopoietic progenitors on the basis of aldehyde dehydrogenase activity. PNAS $969118-9123$. (doi:10.1073/pnas.96.16.9118)

Szotek PP, Pieretti-Vanmarcke R, Masiakos PT, Dinulescu DM, Connolly D, Foster R, Dombkowski D, Preffer F, Maclaughlin DT \& Donahoe PK 2006 Ovarian cancer side population defines cells with stem cell-like characteristics and Mullerian inhibiting substance responsiveness. PNAS 103 11154-11159. (doi:10.1073/pnas.0603672103)

Szotek PP, Chang HL, Brennand K, Fujino A, Pieretti-Vanmarcke R, Lo Celso C, Dombkowski D, Preffer F, Cohen KS, Teixeira J et al. 2008 Normal ovarian surface epithelial label-retaining cells exhibit stem/progenitor cell characteristics. PNAS105 12469-12473. (doi:10.1073/pnas.0805012105)

Tata PR, Mou H, Pardo-Saganta A, Zhao R, Prabhu M, Law BM, Vinarsky V, Cho JL, Breton S, Sahay A et al. 2013 Dedifferentiation of committed epithelial cells into stem cells in vivo. Nature 503 218-223. (doi:10. 1038/nature12777)
Teyssier JR, Couillin P, Benard J, Ravisse N, Ulrich E \& Cornillet P 1992 A multidrug-resistant ovarian carcinoma cell line with a malignant suppressed phenotype is a CD44 gene expression defective mutant. Cancer Genetics and Cytogenetics 60 14-19. (doi:10.1016/01654608(92)90225-W)

Thomson S, Petti F, Sujka-Kwok I, Mercado P, Bean J, Monaghan M, Seymour SL, Argast GM, Epstein DM \& Haley JD 2011 A systems view of epithelial-mesenchymal transition signaling states. Clinical \& Experimental Metastasis 28 137-155. (doi:10.1007/s10585-010-9367-3)

Tonary AM, Macdonald EA, Faught W, Senterman MK \& Vanderhyden BC 2000 Lack of expression of C-KIT in ovarian cancers is associated with poor prognosis. International Journal of Cancer 89 242-250. (doi:10. 1002/1097-0215(20000520)89:3 <242::AID-IJC6 > 3.0.CO;2-6)

Tsai JH, Donaher JL, Murphy DA, Chau S \& Yang J 2012 Spatiotemporal regulation of epithelial-mesenchymal transition is essential for squamous cell carcinoma metastasis. Cancer Cell 22 725-736. (doi:10.1016/ j.ccr.2012.09.022)

Usongo M \& Farookhi R $2012 \beta$-Catenin/Tcf-signaling appears to establish the murine-ovarian surface epithelium (OSE) and remains active in selected postnatal OSE cells. BMC Developmental Biology 1217. (doi:10.1186/1471-213X-12-17)

Virant-Klun I, Skutella T, Hren M, Gruden K, Cvjeticanin B, Vogler A \& Sinkovec J 2013a Isolation of small SSEA-4-positive putative stem cells from the ovarian surface epithelium of adult human ovaries by two different methods. BioMed Research International 2013 690415. (doi:10. 1155/2013/690415)

Virant-Klun I, Skutella T, Kubista M, Vogler A, Sinkovec J \& MedenVrtovec H 2013b Expression of pluripotency and oocyte-related genes in single putative stem cells from human adult ovarian surface epithelium cultured in vitro in the presence of follicular fluid. BioMed Research International 2013 861460. (doi:10.1155/2013/861460)

Wang Y, Sacchetti A, van Dijk MR, van der Zee M, van der Horst PH, Joosten R, Burger CW, Grootegoed JA, Blok LJ \& Fodde R 2012 Identification of quiescent, stem-like cells in the distal female reproductive tract. PLoS ONE 7 e40691. (doi:10.1371/journal.pone.0040691)

Wei X, Dombkowski D, Meirelles K, Pieretti-Vanmarcke R, Szotek PP, Chang HL, Preffer FI, Mueller PR, Teixeira J, MacLaughlin DT et al. 2010 Mullerian inhibiting substance preferentially inhibits stem/progenitors in human ovarian cancer cell lines compared with chemotherapeutics. PNAS 107 18874-18879. (doi:10.1073/pnas.1012667107)

Williams K, Motiani K, Giridhar PV \& Kasper S 2013 CD44 integrates signaling in normal stem cell, cancer stem cell and (pre)metastatic niches. Experimental Biology and Medicine 238 324-338. (doi:10.1177/ 1535370213480714)

Yin G, Alvero AB, Craveiro V, Holmberg JC, Fu HH, Montagna MK, Yang Y, Chefetz-Menaker I, Nuti S, Rossi M et al. 2013 Constitutive proteasomal degradation of TWIST-1 in epithelial-ovarian cancer stem cells impacts differentiation and metastatic potential. Oncogene 32 39-49. (doi:10. 1038/onc.2012.33)

Zhan Q, Wang C \& Ngai S 2013 Ovarian cancer stem cells: a new target for cancer therapy. BioMed Research International 2013 916819. (doi:10. 1155/2013/916819)

Zhang S, Balch C, Chan MW, Lai HC, Matei D, Schilder JM, Yan PS, Huang TH \& Nephew KP 2008 Identification and characterization of ovarian cancer-initiating cells from primary human tumors. Cancer Research 68 4311-4320. (doi:10.1158/0008-5472.CAN-08-0364)

Zhou S, Schuetz JD, Bunting KD, Colapietro AM, Sampath J, Morris JJ, Lagutina I, Grosveld GC, Osawa M, Nakauchi $\mathbf{H}$ et al. 2001 The ABC transporter Bcrp1/ABCG2 is expressed in a wide variety of stem cells and is a molecular determinant of the side-population phenotype. Nature Medicine 7 1028-1034. (doi:10.1038/nm0901-1028)

Zoller M 2011 CD44: can a cancer-initiating cell profit from an abundantly expressed molecule? Nature Reviews. Cancer 11 254-267. (doi:10. 1038/nrc3023)

Received 1 May 2014

First decision 2 June 2014

Revised manuscript received 30 September 2014

Accepted 9 October 2014 